\title{
Fenolni profi lista masline sorte 'Istarska bjelica' pri različitoj koncentraciji bora u hranivoj otopini
}

\section{Sažetak}

Bor (B) je esencijalni biogeni element neophodan za rast i razvoj masline, a nedostatak B općenito se smatra jednim od najčešćih nedostataka mikroelemenata u maslinarstvu. lako nedostatak B može dovesti do promjene koncentracije različitih fenolnih spojeva u listu masline utjecaj ishranjenosti masline $B$ na fenolni profil lista udomaćenih sorata masline nije dovoljno istražen.

Stoga, cilj ovog istraživanja bio je utvrditi utjecaj primjene hranive otopine $s(B+)(30 \mu M B)$ ili bez (B-) $(0$ $\mu \mathrm{M}$ B) bora na fenolni profil lista masline (Olea europaea L.) sorte 'Istarska bjelica'. Pokus je postavljen kao slučajni blokni raspored u četiri ponavljanja na ukupno 40 sadnica masline sorte 'Istarska bjelica'. Uzorkovanje lista provedeno je nakon 60 dana od početka pokusa.

Koncentracija B u listu masline bila je značajno veća u B+ tretmanu, dok su utvrđene koncentracije ukupnih fenola i verbaskozida u listu masline bile značajno veće $u$ B- tretmanu. Gnojidba B nije značajno utjecala na koncentraciju ostalih fenolnih spojeva. Značajno veća koncentracija ukupnih fenola i verbaskozida u listu sorte 'Istarska bjelica' kod B-tretmana može se povezati s fiziološkim odgovorom biljke na nedostatak $B$. Ključne riječi: Olea europaea L., orto-difenoli, cis-dihidroksil molekule, ukupni fenoli, verbaskozid

\section{Uvod}

Maslinarska proizvodnja u Hrvatskoj ima dugotrajnu tradiciju i veliki gospodarski značaj (Gugić i sur., 2010). Maslina se najčešće uzgaja u većim nasadima, a maslinici čine najveći udio površina u voćarskoj proizvodnji (18.683 ha; Statistički ljetopis, 2018). U Hrvatskoj je maslinarska proizvodnja primarno usmjerena proizvodnji ulja $(37.463 \mathrm{hl} / 2017$. godina; Statistički ljetopis, 2018), ali značajno je naglasiti da list masline, iako vrlo vrijedan nusprodukt proizvodnje, ostaje uglavnom neiskorišten.

List masline stoljećima se koristi u narodnoj medicini, a poznato je da sadrži veću koncentraciju pojedinih fenolnih spojeva u usporedbi sa zrelim plodom masline (Silva i sur., 2006). Unatoč tome što je list masline značajan izvor različitih fenolnih spojeva, njegova primjena $u$ proizvodnji lijekova, kozmetike, nutraceutika i funkcionalne hrane tek je nedavno prepoznata (Talhaoui i sur., 2015, Pasković i sur., 2019a).

Fenolni spojevi dio su obrambenog mehanizma masline, a koncentracija pojedinog fenoInog spoja u listu masline mogući je pokazatelj tolerantnosti sorte na specifične bakterijske i gljivične patogene (Markakis i sur., 2010). Verbaskozid je fenolni spoj značajnije zastupljen u sortama masline koje se smatraju tolerantnima na patogene Pseudomonas savastanoi pv. savastanoi i Verticillium dahliae (Markakis i sur., 2010). Također, verbaskozid ima dokazano anti-

\footnotetext{
KristinaGrozić, mag.ing. agr.,dr.sc. IgorPasković, dr.sc. Igor Lukić,Jana Klanjac, mag.ing. agr.,dr.sc. Dean Ban, dr.sc.SmiljanaGoretaBan, Institut za poljoprivredu i turizam, Karla Huguesa 8, 52440 Poreč, Hrvatska dr. sc. Paula Žurga, Nastavni zavod za javno zdravstvo Primorsko-Goranske županije, Krešimirova 52a, 51000 Rijeka, Hrvatska doc. dr. sc.Valerija Majetić Germek, Medicinski fakultet, Sveučilište u Rijeci, Hrvatska, Braće Branchetta 20, 51000 Rijeka, Hrvatska dr. sc. Mia Brkljača, Sveučilište u Zagrebu, Prehrambeno-Biotehnološki fakultet, Pierottijeva 6, Zagreb, 10000 dr. sc. Branimir Urlić, Institut za jadranske kulture i melioraciju krša, Put Duilova 11, Split, 21000, Hrvatska Šime Marcelić, mag. ing. agr., Sveučilište u Zadru, Odjel za ekologiju, agronomiju i akvakulturu, Zadar, Hrvatska doc. dr. sc. Joško Kaliterna, prof. dr. sc. Mirjana Herak Ćustić, Sveučilište u Zagrebu, Agronomski fakultet, Svetošimunska cesta 25, 10000 Zagreb, Hrvatska Autorza korespondenciju: paskovic@iptpo.hr
} 
kancerogeno, protuupalno i antimikrobno djelovanje što omogućuje primjenu lista masline u medicinske svrhe (Tekaya i sur., 2016).

Bor (B) je esencijalan biogeni element čiji nedostatak može značajno ograničiti rast, razvoj, prinos i kvalitetu ploda masline (Fernández-Escobar, 2016). Folijarna primjena gnojiva s B uobičajena je praksa u maslinarskoj proizvodnji (Perica i Čmelik, 2007), međutim odgovor masline na nedostatak B nije dovoljno istražen (Chatzissavvidis i Therios, 2010). Bor sudjeluje u različitim fiziološkim i biokemijskim procesima u stanicama (Mousavi i Motesharezadeh, 2020), a metabolizam fenolnih spojeva jedan je od tih procesa (Broadley i sur., 2012). Poznato je da nedostatak B može utjecati na promjene u fenolom profilu biljke (Tekaya i sur., 2016). Naime, nedostatak $B$ može dovesti do povećanja koncentracije fenola u listu masline različitim mehanizmima, poput: i) indukcije fenilpropanoidnog biosintetskog puta reduciranjem porasta biljke i ugradnjom ligninskih perkursora, ii) povećanjem aktivnosti fenilalanin-amonij-lijaze (PAL), iii) povećanjem koncentracije fenolnih kiselina (cis-dihidroksil struktura) koje formiraju kompleks cis-dihidroksil-borata s citoplazmatskom bornom kiselinom (Liakopoulos i Karabourniotis, 2005).

U maslinarskoj proizvodnji Hrvatske, jedna od najzastupljenijih udomaćenih sorata je 'Istarska bjelica' (Benčić i sur., 2009). Značajne karakteristike ove sorte su visoki sadržaj fenola i tolerantnost na pojedine abiotičke i biotičke stresove (Perica i sur., 2008; Benčić i sur., 2009). Ipak, prema dostupnoj literaturi, utjecaj ishranjenosti B na fenolni profil lista masline sorte 'Istarske bjelica' do sada nije istražen (Liakopoulos i Karabourniotis, 2005; Hegazi i sur., 2018; Pasković i sur., 2019a).

Stoga, provedeno istraživanje imalo je za cilj utvrditi utjecaj primjene hranive otopine $S$ $(\mathrm{B}+)$ ili bez (B-) bora na koncentraciju ukupnih fenola kao i pojedinačnih fenolnih spojeva lista masline sorte 'Istarska bjelica'.

\section{Materijal i metode}

Pokus je postavljen na šest mjeseci starim sadnicama masline sorte 'Istarska bjelica'. Nakon ispiranja korijena, sadnice su presađene u lonce zapremnine 3,5 L, koji su sadržavali neutralnu smjesu perlita i kvarcnog pijesaka u jednakom omjeru. Sadnice masline uzgajane su u plasteniku Instituta za poljoprivredu i turizam (Poreč, Hrvatska) tijekom ljeta 2018. godine.

Pokus je postavljen kao slučajni blokni raspored s dva gnojidbena tretmana: (I) hraniva Hoaglandova otopina bez bora (B-); (II) hraniva Hoaglandova otopina s borom (B+) (30 $\mu \mathrm{M} \mathrm{B}), \mathrm{u}$ četiri ponavljanja (Hoagland i Arnon, 1950). Ukupan broj biljaka u pokusu bio je 40.

Dinamika primjene hranivih otopina prilagođena je klimatskim uvjetima i potrebama presadnica. Nakon 60 dana trajanja pokusa listovi su uzorkovani sa središnjeg dijela mladice. Prikupljeni listovi prvo su oprani u običnoj vodi, zatim u deioniziranoj vodi uz dodatak $1 \%$ octene kiseline te završno samo u deioniziranoj vodi (Pasković i sur., 2019b). Listovi za daljnje analize sušeni su na zraku do konstantne težine.

Uzorci biljnog materijala pripremljeni su suhim spaljivanjem u mufolnoj peći. Sitno samljeveni list sušen je na $80^{\circ} \mathrm{C} \mathrm{kroz} 48$ sati, a zatim je do vaganja držan na $60^{\circ} \mathrm{C}$ (Delgado i sur., 1994). Vagano je 0,5 g uzorka u porculanske lončiće koji su 24 sata držani u otopini s 10 \% klorovodičnom kiselinom ( $\mathrm{V}: \mathrm{V})$. Lončići s listom stavljeni su na žarenje u mufolnu peć koja je zagrijavana $2{ }^{\circ} \mathrm{C} / \mathrm{min}$ do $550{ }^{\circ} \mathrm{C}$ i na toj temperaturi je žareno 8 sati. Pepeo je otopljen dodatkom $5 \mathrm{ml} 6 \mathrm{M}$ klorovodične kiseline, a lončić je zagrijavan na električnom kuhalu oko 15 min na $500^{\circ} \mathrm{C}$. Zatim 
se otopina filtrirala u PE epruvete i nadopunila destiliranom vodom do $50 \mathrm{ml}$ (Stateras i Moustakas, 2017). Koncentracija B u listu određena je pomoću masenog spektrometra s induktivno spregnutom plazmom (ICP-MS) Nexion 300x (PerkinElmer Instruments, Waltham, MA, SAD).

Pojedinačni fenoli određeni su metodom tekućinske kromatografije visoke djelotvornosti (HPLC) pomoću Thermo Ultimate 3000 sustava (ThermoFisher Scientific, Waltham, MA, SAD). Analitička kolona bila je Lichrospher 100 RP-18 (250 mm x 4 mm, $5 \mu \mathrm{m}$ ) s predkolonom Lichrospher 100 (4x4 mm, $5 \mu \mathrm{m}$ ) (Agilent Technologies, Santa Clara, CA, SAD). Mobilna faza sastojala se od dvije tekuće faze: (A) 0,2\% fosforne kiseline i (B) metanol:acetonitril (1:1, V:V). Identifikacije su provedene uspoređujući vremena zadržavanja ciljanih spojeva u ekstraktima uzoraka s vremenima zadržavanja čistih standarda.

Maseni udjeli ukupnih fenola u lišću određeni su prema metodi Marinova i sur. (2005). Optička gustoća određena je UV/VIS spektrofotometrom (HACH DR/400, Colorado, SAD) nakon reakcije ekstrakta fenolnih tvari s Folin-Ciocalteu reagensom. Apsorbancije su izmjerene na $750 \mathrm{~nm}$.

Podatci su obrađeni analizom varijance (ANOVA) dok je za višestruku usporedbu srednjih vrijednosti tretmana primijenjen Tukeyev post-hoc test. Statistička analiza provedena je statističkim računalnim programom Statistica (13.3, Tibco, Inc.).

\section{Rezultati i rasprava}

Analizom koncentracije B u listu sadnica masline sorte 'Istarska bjelica', utvrđene su značajno veće koncentracije bora u B+ tretmanu $(27 \mathrm{mg} / \mathrm{kg}$ suhe tvari (ST)) u odnosu na B- tretman (17 mg/kg ST; Grafikon 1). Optimalnom koncentracijom B u listu masline smatra se raspon od 19 do 150 mg/kg ST (Fernández-Escobar, 2019), ali ona se može značajno razlikovati između sorata masline (Failla i sur., 2004). Tako Fernández-Escobar i sur. (2016) navode da su se simptomi nedostatka B kod sadnica sorte 'Picual' razvili pri koncentraciji nižoj od $33 \mathrm{mg} / \mathrm{kg}$ ST, dok Pasković i sur. (2019a) i pri dvostruko nižim koncentracijama nisu zabilježili simptome nedostatka B kod sorte 'Leccio del Corno'.

U ovom istraživanju koncentracija ukupnih fenola bila je značajno veća u B- tretmanu (2034 mg/100g ST) u odnosu na B+ tretman (1779 mg/100g ST; Grafikon 1). Liakopoulos i Karabourniotis (2005) navode da je nedostatak B uzrokovao značajno nakupljanje pojedinačnih fenoInih komponenata i ukupnih fenola u listovima dvogodišnjih sadnica masline sorte 'Manaki' uzgajanih u polu-hidroponskom sustavu.

Koncentracija jednostavnih fenola (hidroksitirosola, tirosola) i sekoiridoida oleuropeina nije se razlikovala između gnojidbenih tretmana (Tablica 1). Oleuropein se često smatra najdominantnijim spojem u listu masline (Tekaya i sur., 2016). Ipak, rezultati ovog istraživanja pokazali su nižu koncentraciju oleuropeina (46-53 mg/ $100 \mathrm{~g} \mathrm{ST}$ ) u odnosu na razinu hidroksitirosola (203-229 mg/100 g ST) ili luteolina (88-91 mg/100 g ST; Tablica 1, Tablica 2). Pasković i sur. (2019a) zaključuju da folijarna primjena B nije imala značajan utjecaj na promjenu koncentracije jednostavnih fenola u listu masline sorte 'Leccio del Corno'.

Koncentracija verbaskozida bila je signifikantno veća u B- (117 mg/100 g ST) u odnosu na B+ tretman (42 mg/100 g ST; Tablica 3). lako tijekom ovog istraživanja na biljkama nisu uočeni specifični simptomi nedostatka $B$, poput apikalne kloroze ili novih listova u obliku rozete (Fernández-Escobar i sur., 2016), poznato je da se nedostatak B može povezati s nakupljanjem fenolnih kiselina s cis-dihidroksil strukturom koje formiraju kompleks cis-dihidroksil-borata (Liakopoulos i Karabourniotis, 2005). Nedostatak B može dovesti do smanjenog stvaranja cisdihidroksil-borata što posljedično rezultira povećanom dostupnosti molekula s cis-dihidroksil strukturom. Upravo orto-difenoli, među koje ubrajamo i verbaskozid, najvažniji su predstavnici takvih spojeva (Haissig, 1986; Soufi i sur., 2014). Verbaskozid se smatra značajnim fenolnim 
spojem u odgovoru masline na sprečavanje razvoja bakterijskih i gljivičnih bolesti (Markakis i sur., 2010).
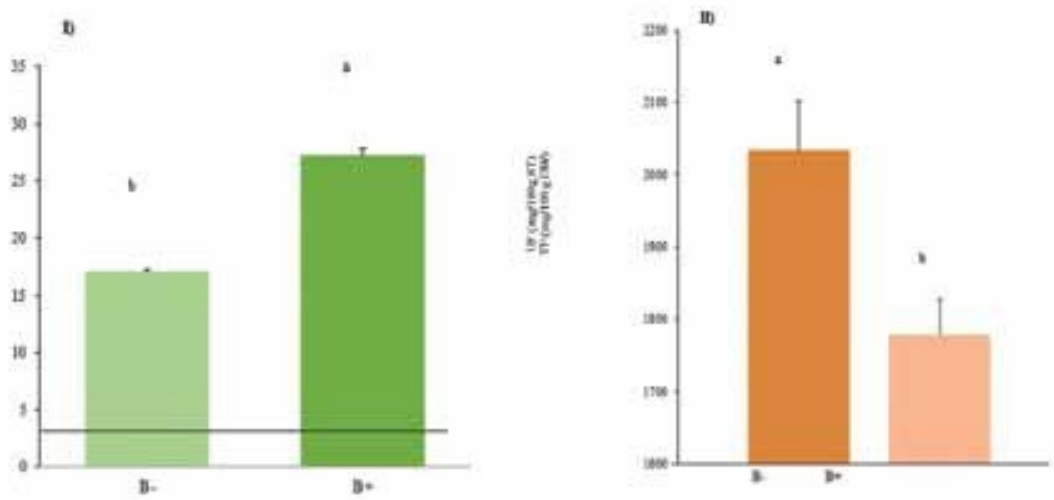

Grafikon 1. Utjecaj primjene bora (B) na koncentraciju bora (B) (I) i ukupnih fenola (UF) (II) u listovima masline

Fig. 1. The effect of boron (B) application on B concentration in olive leaves (B) (I) and total phenolic content (TP) (II)

Srednje vrijednosti označene drukčijim slovima značajno su različite uz $p<0,05$ prema Tukey testu (srednje vrijednosti $\pm S E, n=4$ )

Mean values followed by different letters are significantly different at $p<0.05$ according to Tukey's test (mean values $\pm S E, n=4$ )

Koncentracija katehina (13-14 mg/100 g ST), rutina (26-28 mg/100 g ST), luteolin-7-O-glukozida (18 mg/100 g ST), apigenin-7-O-glukozida (2-3 mg/100 g ST), luteolina i apigenina (7 $\mathrm{mg} / 100 \mathrm{~g} \mathrm{ST}$ ) nije se signifikantno razlikovala između tretmana (Tablica 2). Također, u koncentracijama vanilinske kiseline (2 mg/100 g ST), 4-hidroksibenzojeve kiseline (3-4 mg/100 g ST), kavske kiseline ( $3 \mathrm{mg} / 100 \mathrm{~g} \mathrm{ST}$ ) i ferulinske kiseline ( $2 \mathrm{mg} / 100 \mathrm{~g} \mathrm{ST}$ ) nisu utvrđene signifikantne razlike između $\mathrm{B}-\mathrm{i} \mathrm{B}+$ tretmana (Tablica 3 ).

Tablica 1. Utjecaj primjene bora (B) na koncentraciju hidroksitirosola, tirosola i oleuropiena u listovima masline

Table 1. The effect of boron (B) application on hydroxytyrosol, tyrosol and oleuropein concentration in olive leaves

\begin{tabular}{llcl}
\hline $\begin{array}{l}\text { Tretman/ } \\
\text { Treatment }\end{array}$ & Hidroksitirosol/Hydroxytyrosol & \multicolumn{1}{c}{$\begin{array}{c}\text { Tirosol/Tyrosol } \\
\mathrm{mg} / 100 \mathrm{~g} \mathrm{ST} / \mathrm{mg} / 100 \mathrm{~g} \mathrm{DW}\end{array}$} \\
\hline B- & $229,36 \pm 8,46$ & $25,15 \pm 0,82$ & Oleuropein/Oleuropein \\
\hline B+ & $202,60 \pm 10,42$ & $25,68 \pm 1,53$ & $53,25 \pm 3,62$ \\
\hline$p$ & n.s. & n.s. & n.s. \\
\hline
\end{tabular}

Srednje vrijednosti označene drukčijim slovima značajno su različite uz $p<0,05$ prema Tukey testu (srednje vrijednosti $\pm S E, n=4$ )

Mean values followed by different letters are significantly different at $p<0.05$ according to Tukey's test (mean values $\pm \mathrm{SE}, \mathrm{n}=4$ ) 
Tablica 2. Utjecaj primjene bora (B) na koncentraciju flavonoida u listovima masline

Table 2. The effect of boron (B) application on the concentration of $\mathrm{fl}$ vonoids in olive leaves

\begin{tabular}{lllllll}
\hline & \multicolumn{1}{c}{ Flavonoidi (mg/100 g ST)/Flavonoids (mg/100 g DW) } \\
\cline { 2 - 7 } $\begin{array}{l}\text { Tretman/ } \\
\text { Treatment }\end{array}$ & $\begin{array}{l}\text { Katehin/ } \\
\text { Catechin }\end{array}$ & $\begin{array}{l}\text { Rutin/ } \\
\text { Rutin }\end{array}$ & $\begin{array}{l}\text { Luteolin-7- } \\
\text { O-glukozid/ } \\
\text { Luteolin-7-O- } \\
\text { glucoside }\end{array}$ & $\begin{array}{l}\text { Apigenin-7-O-glukozid/ } \\
\text { Apigenin-7-O-glucoside }\end{array}$ & $\begin{array}{l}\text { Luteolin/ } \\
\text { Luteolin }\end{array}$ & $\begin{array}{l}\text { Apigenin/ } \\
\text { Apigenin }\end{array}$ \\
\hline B- & $12,82 \pm 0,88$ & $27,85 \pm 1,94$ & $18,32 \pm 1,05$ & $2,64 \pm 0,08$ & $88,48 \pm 4,79$ & $6,95 \pm 0,52$ \\
\hline B+ & $14,20 \pm 0,65$ & $25,85 \pm 2,81$ & $17,63 \pm 0,81$ & $2,41 \pm 0,13$ & $90,55 \pm 2,65$ & $7,28 \pm 0,32$ \\
\hline
\end{tabular}

Srednje vrijednosti označene drukčijim slovima značajno su različite uz $p<0,05$ prema Tukey testu (srednje vrijednosti $\pm S E, n=4$ ).

Mean values followed by different letters are significantly different at $p<0.05$ according to Tukey's test (mean values $\pm S E, n=4$ ).

Tablica 3. Utjecaj primjene bora (B) na koncentraciju fenolnih kiselina u listovima masline

Table 3. The effect of boron (B) application on the concentration of phenolic acids in olive leaves

\begin{tabular}{llllll}
\hline & \multicolumn{2}{l}{ Fenolne kiseline (mg/100 g ST)/Phenolic acids (mg/100g DW) } \\
\cline { 2 - 6 } $\begin{array}{l}\text { Tretman/ } \\
\text { Treatment }\end{array}$ & $\begin{array}{l}\text { Vanilinska kiselina/ } \\
\text { Vanillic acid }\end{array}$ & $\begin{array}{l}\text { Verbaskozid/ } \\
\text { Verbascoside }\end{array}$ & $\begin{array}{l}\text { 4-hidroksibenzojeva kiselina/ } \\
\text { 4-hydroxybenzoic acid }\end{array}$ & $\begin{array}{l}\text { Kavska } \\
\text { kiselina/ } \\
\text { Caffeic acid }\end{array}$ & $\begin{array}{l}\text { Ferulinska } \\
\text { kiselina/ } \\
\text { Ferrulic acid }\end{array}$ \\
\hline B- & $1,83 \pm 0,08$ & $116,93 \pm 16,33^{\text {a }}$ & $3,89 \pm 0,18$ & $2,68 \pm 0,08$ & $1,59 \pm 0,11$ \\
\hline B+ & $1,91 \pm 0,09$ & $42,42 \pm 9,26^{\text {b }}$ & $3,46 \pm 0,17$ & $2,57 \pm 0,01$ & $1,67 \pm 0,14$ \\
\hline
\end{tabular}

Srednje vrijednosti označene drukčijim slovima značajno su različite uz $p<0,05$ prema Tukey testu (srednje vrijednosti $\pm S E, n=4$ ).

Mean values followed by different letters are significantly different at $p<0.05$ according to Tukey's test (mean values $\pm S E, n=4$ )

\section{Zaključci}

Dodatak B $(30 \mu \mathrm{M})$ u hranivu otopinu, kojom su tijekom 60 dana prihranjivane sadnice masline, doveo je do povećanja koncentracije B u listu (27 mg/kg ST) u odnosu na sadnice koje su prihranjivane otopinom bez B (17 mg/kg ST). Pritom, kod sadnica prihranjenih hranivom otopinom bez B utvrđeno je značajno povećanje koncentracije ukupnih fenola i verbaskozida.

Razlike u koncentraciji ostalih fenolnih kiselina, flavonoida, jednostavnih fenola i oleuropeina nisu utvrđene između B+ ili B- tretmana.

\section{Zahvala}

Ovaj rad je sufinancirala Hrvatska zaklada za znanost projektom "Bilinogojstvom do sekundarnih biljnih metabolita: primjena mineralnih hraniva i elicitora za povećanje koncentracije fenola u listu masline" (UIP-2017-05-8464).

Rad doktorandice Kristine Grozić sufinanciran je iz "Projekta razvoja karijera mladih istraživača - izobrazba novih doktora znanosti" Hrvatske zaklade za znanost (DOK-2018-09-1841). 


\section{Literatura}

Benčić, Đ., Cukon, J., Gunjača, J. (2009) Morfološka različitost fenotipova masline (Olea europaea L.) lokalnog naziva "Bjelice" u Istri. Sjemenarstvo, 26 (1-2), 39-46. URL: https://core.ac.uk/download/pdf/14419133.pdf (09.6.2020.)

Broadley, M., Brown, P., Cakmak, I., Rengel, Z., Zhao, F. (2012) Function of Nutrients: Micronutrients. U: Marschner, P., ur. Marschner's Mineral Nutrition of Higher Plants. London, UK, Academic Press, Elsevier.

Chatzissavvidis, C., Therios, I. (2010) Response of four olive (Olea europaea L.) cultivars to six B concentrations: Growth performance, nutrient status and gas exchange parameters. Scientia Horticulturae, 127, 39-38. DOI: https://doi. org/10.1016/i.scienta.2010.09.008

Delgado, A., Benlloch, M., Fernández-Escobar, R. (1994) Mobilization of boron in olive trees during flowering and fruit development. HortScience, 29 (6), 616-618. DOI: https://doi.org/10.21273/HORTSCI.29.6.616

Failla, O., Pedò, S., Bassi, D., Gigliotti, C. (2004) Determination of olive leaf boron critical levels in northern Italy. U: $V$ International Symposium on Olive Growing 791, 763-768. DOI: 10.17660/ActaHortic.2008.791.116

Fernández-Escobar, R. (2016) Trends in olive nutrition. U: Perica, S., Vuletin Selak, G., Klepo, T., Ferguson, L., Sebastiani, L.,, ur. VIII International Olive Symposium, Split, 30.4.2018.ISHS Acta Horticulturae 1199,, 215-224. DOI: 10.17660/ ActaHortic.2018.1199.35

Fernández-Escobar, R. (2019) Olive Nutritional Status and Tolerance to Biotic and Abiotic Stresses. Frontiers in Plant Science, 10, 1151. DOI: https://doi.org/10.3389/fpls.2019.01151

Gugić, J., Tratnik, M., Strikić, F., Gugić, M., Kursan, P. (2010) Pregled stanja i perspektiva razvoja hrvatskoga maslinarstva. Pomologia Croatica: Glasilo Hrvatskog agronomskog društva, 16 (3-4), 121-146. URL: https://hrcak.srce.hr/ index.php?show=clanak\&id_clanak_jezik=103019 (07.6.2020.)

Haissig, B. E. (1986) Metabolic processes in adventitious rooting of cuttings. U: Jackson, M.B., ur. New root formation in plants and cuttings. Dordrecht: Springer. DOI: https://doi.org/10.1007/978-94-009-4358-2_5

Hegazi, E. S., El-Motaium, R. A., Yehia, T. A., Hashim, M. E. (2018) Effect of foliar boron application on boron, chlorophyll, phenol, sugars and hormones concentration of olive (Olea europaea L.) buds, leaves, and fruits. Journal of Plant Nutrition, 41(6), 749-765. DOI: https://doi.org/10.1080/01904167.2018.1425438

Hoagland, D.R., Arnon, D.S. (1950) The water culture method for growing plants without soil. Calif. Agric. Exp. Stat. Circ., 374. URL: https://www.cabdirect.org/cabdirect/abstract/19500302257 (10.4.2019.)

Liakopoulos, G., Karabourniotis, G. (2005) Boron deficiency and concentrations and composition of phenolic compounds in Olea europaea leaves: a combined growth chamber and field study. Tree physiology, 25 (3), 307-315. DOI: https://doi.org/10.1093/treephys/25.3.307

Marinova, D., Ribarova, F., Atanassova, M. (2005) Total phenolics and total flavonoids in Bulgarian fruits and vegetables. J. Univ. Chem. Technol. Metall., 40 (3), 255-260.

Markakis, E.A., Tjamos, S.E., Antoniou, P.P. Roussos, P.A. Paplomatas, E.J., Tjamos, E.C. (2010) Phenolic Responses of Resistant and Susceptible Olive Cultivars Induced by Defoliating and Nondefoliating Verticillium dahliae Pathotypes. Plant Disease, 94 (9), 1156-1162. DOI: https://doi.org/10.1094/PDIS-94-9-1156

Mousavi, S.M., Motesharezadeh, B. (2020) Boron deficiency in fruit crops. U: Srivastava A.K., Hu, C., ur. Fruit Crops: Diagnosis and Management of Nutrient Constraints. Amsterdam: Netherlands: Elseiver.

Pasković, I., Soldo, B., Talhaoui, N., Palčić, I., Brkljača, M., Koprivnjak, O., Majetić Germek, V., Ban, D., Klanjac, J., Franić, M., Žurga, P., Grozić, K., Lukić, I., Goreta Ban, S. (2019a) Boron foliar application enhances oleuropein level and modulates volatile compound composition in olive leaves. Scientia Horticulturae, 257, 108688. DOI: https://doi.org/10.1016/j. scienta.2019.108688

Perica, S., Čmelik, Z. (2007) Utjecaj folijarne gnojidbe dušikom, kalijem i borom na razinu i sezonsku promjenjivost koncentracija dušika, kalija i bora u lišću masline sorte Oblica. Pomologia Croatica: Glasilo Hrvatskog agronomskog društva, 13 (2), 63-75. URL: https://hrcak.srce.hr/26635 (27.5.2020.)

Perica, S., Goreta, S., Vuletin Selak, G. (2008) Growth, biomass allocation and leaf ion concentration of seven olive (Olea europaea L.) cultivars under increased salinity. Scientia horticulturae, 117 (2), 123-129. DOI: https://doi. org/10.1016/j.scienta.2008.03.020

Silva, S., Gomes, L., Leitao, F., Coelho, A.V., Boas, L. V. (2006) Phenolic compounds and antioxidant activity of Olea europaea L. fruits and leaves. Food Science and Technology International, 12, 385-396. DOI: https://doi. org/10.1177/1082013206070166

Soufi, O., Romero, C., Louaileche, H.(2014) Ortho-diphenolprofileandantioxidantactivityof Algerianblackolivecultivars: Effect of dry salting process. Food chemistry, 157, 504-510. DOI: https://doi.org/10.1016/j.foodchem.2014.02.075

Stateras, D.C., Moustakas, N.K. (2017) Seasonal changes of macro- and micro-nutrients concentration in olive leaves. Journal of Plant Nutrition, 41 (2), 1-11. DOI: https://doi.org/10.1080/01904167.2017.1383421

Statistički ljetopis Republike Hrvatske (2018) 263-264. URL: https://www.dzs.hr/Hrv/Publication/stat_year.htm (07.6.2020.)

Talhaoui, N., Taamalli, A., Gómez-Caravaca, A. M., Fernández-Gutiérrez, A., Segura-Carretero, A. (2015) Phenolic compounds in olive leaves: Analytical determination, biotic and abiotic influence, and health benefits. Food Research International, 77, 92-108. DOI: https://doi.org/10.1016/j.foodres.2015.09.011

Tekaya, M., El-Gharbi, S., Mechri, B., Chehab, H., Behir, A., Chraief, I., Ayachi, M., Boujnah, D., Attia, F., Hammami, M. (2016) Improving performance of olive trees by the enhancement of key physiological parameters of olive leaves in response to foliar fertilization. Acta Physiologiae Plantarum, 38, 101. DOI: https://doi.org/10.1007/s11738-016-2122-x

Prispjelo/Received: 3.7.2020.

Prihvaćeno/Accepted: 3.9.2020. 


\section{Phenolic leaf profile of olive cultivar 'Istarska bjelica' at different boron concentrations in the nutrient solution}

\section{Abstract}

Boron $(B)$ is an essential nutrient for growth and development of olive, whereas $B$ deficiency is among the most common micronutrient disorders in olive production. Boron deficiency contributes changes in the concentration of different phenolic compounds in olive leaves, the impact of $B$ nutrition on the phenolic leaf profile of autochthonous olive varieties is mainly unknown.

This study aimed to investigate the impact of nutrient solutions, with $(B+)$ and without $(B-)$ boron addition, on the phenolic profile in olive leaves of cultivar 'Istarska bjelica'.

The experiment was set up in random block design in four repetitions, on 40 olive plantlets of cultivar 'Istarska bjelica'. Olive leaves were sampled 60 days after the beginning of the experiment.

Boron concentration in olive leaves was significantly higher in the B+ treatment, whereas total phenolic content and verbascoside concentration were significantly higher in the olive leaves of the B-treatment. Boron nutrition had no significant impact on other phenolic compounds.

A significantly higher total phenolic content and verbascoside concentration, determined in olive leaves of cultivar 'Istarska bjelica', indicate the relation between physiological plant response and B deficiency.

Keywords: Olea europaea L., ortho-diphenol, cis-hydroxyl groups, total phenolic content, verbascoside

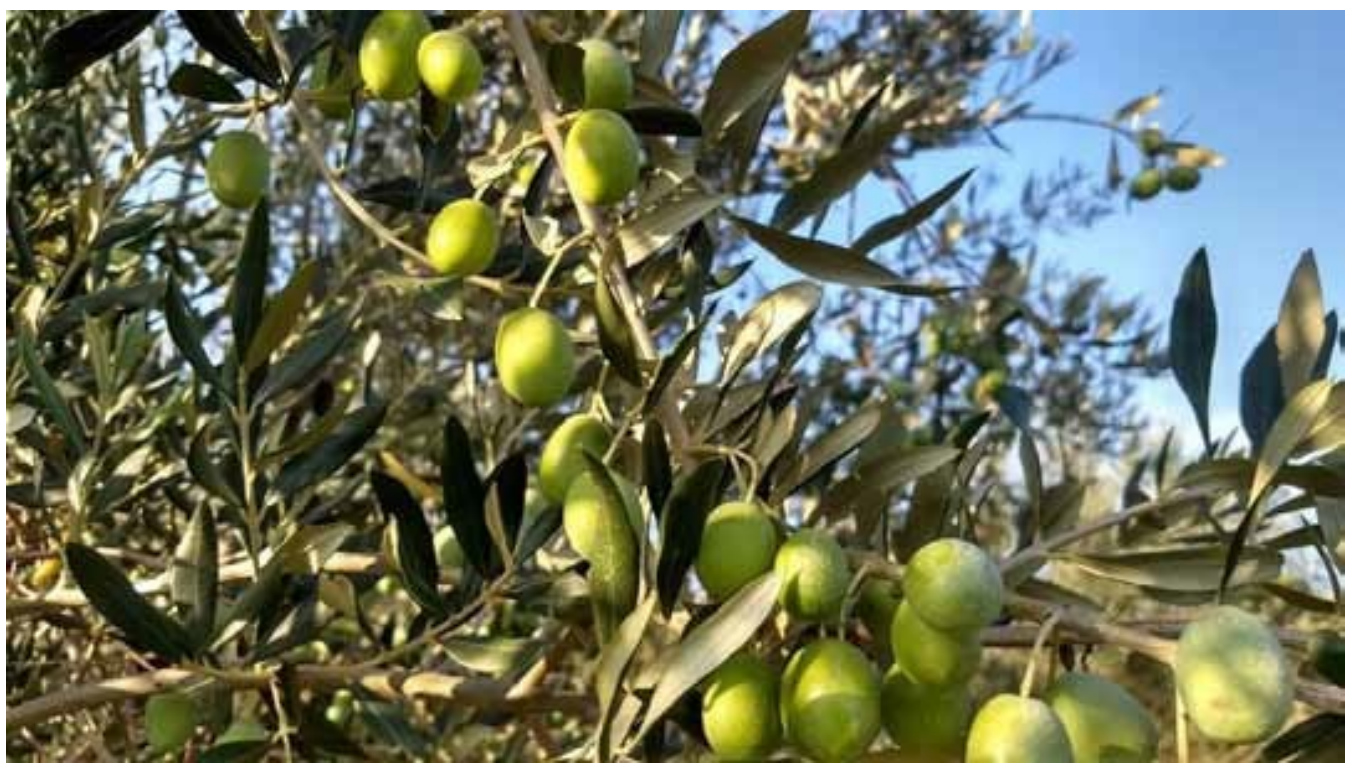

